\title{
RNA profiles of rat olfactory epithelia: individual and age related
} variations

\author{
Maud Rimbault ${ }^{1,2}$, Stéphanie Robin ${ }^{1,2}$, Amaury Vaysse ${ }^{1,2}$ and \\ Francis Galibert*1,2
}

Address: ${ }^{1}$ Université de Rennes 1, Institut de Génétique et Développement de Rennes, UEB, Faculté de Médecine, Rennes, France and ${ }^{2}$ UMR 6061 Institut de Génétique et Développement de Rennes, CNRS - Université Rennes 1, Rennes, France

Email: Maud Rimbault - maud.rimbault@univ-rennes1.fr; Stéphanie Robin - stephanie.robin@univ-rennes1.fr; Amaury Vaysse - amaury.vaysse@univ-rennes1.fr; Francis Galibert* - francis.galibert@univ-rennes1.fr

* Corresponding author

Published: 2 December 2009

BMC Genomics 2009, 10:572
Received: 21 August 2009

Accepted: 2 December 2009

This article is available from: http://www.biomedcentral.com/I47I-2/64/I0/572

(c) 2009 Rimbault et al; licensee BioMed Central Ltd.

This is an Open Access article distributed under the terms of the Creative Commons Attribution License (http://creativecommons.org/licenses/by/2.0), which permits unrestricted use, distribution, and reproduction in any medium, provided the original work is properly cited.

\begin{abstract}
Background: Mammalian genomes contain a large number ( 1000) of olfactory receptor (OR) genes, many of which (20 to $50 \%$ ) are pseudogenes. OR gene transcription is not restricted to the olfactory epithelium, but is found in numerous tissues. Using microarray hybridization and RTqPCR, we analyzed the mRNA profiles of the olfactory epithelium of male and female Brown Norway rats of different origins and ages (newborn, adult and old).

Results: (I) We observed very little difference between males and females and between rats from two different suppliers. (2) Different OR genes were expressed at varying levels, rather than uniformly across the four endoturbinates. (3) A large proportion of the gene transcripts ( $2 / 3$ of all probes) were detected in all three age groups. Adult and older rats expressed similar numbers of OR genes, both expressing more OR genes than newborns. (4) Comparisons of whole transcriptomes or transcription profiles of expressed OR genes only showed a clear clustering of the samples as a function of age. (5) Most OR genes were expressed at lower levels at birth than in older animals, but a small number of $O R$ genes were expressed specifically or were overexpressed in newborns.

Conclusion: Not all OR genes are expressed at a detectable level. Pups expressed fewer OR genes than adult rats, and generally at a lower level; however, a small subset of OR genes were more strongly expressed in these newborn rats. The reasons for these differences are not understood. However, the specific expression of some OR genes in newborn olfactory epithelia may be related to the blindness and deafness of pups at birth, when these pups are heavily reliant on olfaction and their mother.
\end{abstract}

\section{Background}

Olfactory receptor (OR) genes were first identified in the rat nasal epithelium by Buck and Axel in 1991 [1]. The receptors they encode play an essential role in olfaction, constituting a key initial element in a cascade of biochemical reactions that lead to odorant perception and recognition. Gene cloning and in silico mining of a number of mammalian genome sequences have identified about 800 
OR intact genes and pseudogenes in the human genome $[2,3]$ and up to 1500 OR genes (including pseudogenes) in the rat genome [4]. Indeed, these genes constitute by far the largest gene family in mammalian genomes.

A substantial percentage of OR genes -- 50\% in humans [5], 24\% in mouse [6], 20.3\% in dog and $19.5 \%$ in rat [4] -- are pseudogenes. However, the distinction between pseudogenes and potentially active genes is not strictly defined: for example, a particular gene may exist as either a pseudogene or a potentially active gene, depending upon the population or the individual, as shown for dogs [7] and for humans [8].

Only a small number of OR proteins have been deorphanized, i.e. the ligand that they bind to has been identified, and the role of the vast majority of these proteins in olfaction remains undefined. Cloning experiments and microarray analyses have added an additional layer of complexity by showing that at least some pseudogenes can be transcribed $[9,10]$ and that the transcription of OR genes is not necessarily restricted to the nasal mucosa, but is also detected in several other tissues, including testis [11] and kidney [12].

ORs are expressed on the surface of the cilia of olfactory sensory neurons (OSNs) lining the neuroepithelium in the nasal cavity, the site of odorant inhalation [13]. Each OSN expresses one OR from a single allele [14-18]; their axons extend to the olfactory bulb, where the axons of all OSN expressing the same OR converge on a single glomerulus [19-21]. The mechanism by which axons of OSNs expressing the same OR, but dispersed along the olfactory epithelium, converge on the same glomerulus is not totally understood. However, ORs that are not restricted to OSN cilia, but which are also present at the tip of the axons $[22,23]$ contribute, together with other proteins, to the coalescence of the axons [21,24-26].

Studies based on cDNA library analysis and microarray hybridization have shown that only a subset of the mouse OR gene repertoire is expressed at detectable levels in the olfactory epithelium $[9,27]$. In humans, the pattern of transcription differs slightly between individuals [10]. The importance of such differences is not known. In particular, it is unclear whether these differences reflect individual differences in sensory function, possibly related to some form of anosmia or hyperosmia, or whether they reflect environmental differences. In this study, we carried out hybridization on whole rat genome microarrays, to analyze the transcriptome of the olfactory epithelium of adult Brown Norway rats of different origins and sex. The transcriptomes of these rats were then compared with those of newborn and aged rats, to investigate changes associated with aging.

\section{Results and Discussion \\ I - The olfactory epithelium transcriptome of adult Brown Norway rats}

We determined the gene expression profiles of olfactory epithelia from six-week-old rats not exposed to a particular odorant (naive animals). We purchased four Brown Norway rats (two males and two females) from Elevage Janvier and four rats of the same strain (two males and two females) from Charles River Laboratories. After their arrival, the animals were kept in the animal house for one week and were then killed. Total RNA was extracted from left and right olfactory epithelia, labeled and used for hybridization on Agilent Whole Rat Genome 44K microarrays, as described in the Methods section. Microarrays were scanned and probes were assigned to three groups: "expressed", "weakly expressed" and "not expressed" (Figure 1).

Of all the probes spotted on the array, 26,701 (65\%) gave a signal above background for at least 11 of the 15 samples $(\geq 73 \%)$ (Figure 2 ). These probes were considered to correspond to the set of genes expressed to detectable levels. They included 732 of the 1136 OR genes spotted on the array (from a total of 1201 rat OR genes with an intact open reading frame [4]; see additional file 1 for the OR gene list).

For probes that did not give either a positive or negative signal (above or below background levels, respectively) for all samples, we compared the signal status of each probe (positive or negative) in the right and left samples from each rat. We observed two different scenarios for the 14 samples (corresponding to seven rats from which we obtained the right and left samples): identical responses in the left and right samples, and different responses for the left and right samples. For 668 probes, we observed a $12+/ 2$ - distribution (12 samples showing positive signal and two showing negative results); for 83 of these 668 probes, the two negative results were obtained for left and right samples from the same rat. Similarly, a 12-/2+ distribution of negative and positive signal was observed for 383 probes; 105 of these probes yielded two positive results for the left and right samples from a single rat. Statistical analysis (binomial test, $p$ value $<10^{-4}$ ) of the data clearly demonstrated that both negative and positive results were more frequently paired (right and left samples from the same animal giving identical results) than would be expected if the distribution were random. Probes giving different results for different samples presumably corresponded to two groups of transcripts: one corresponding to a group of genes poorly expressed at levels close to the detection limit of the method used, generating a random distribution of negative and positive results; and a second group corresponding to genes giving the same results for the right and left samples of an indi- 


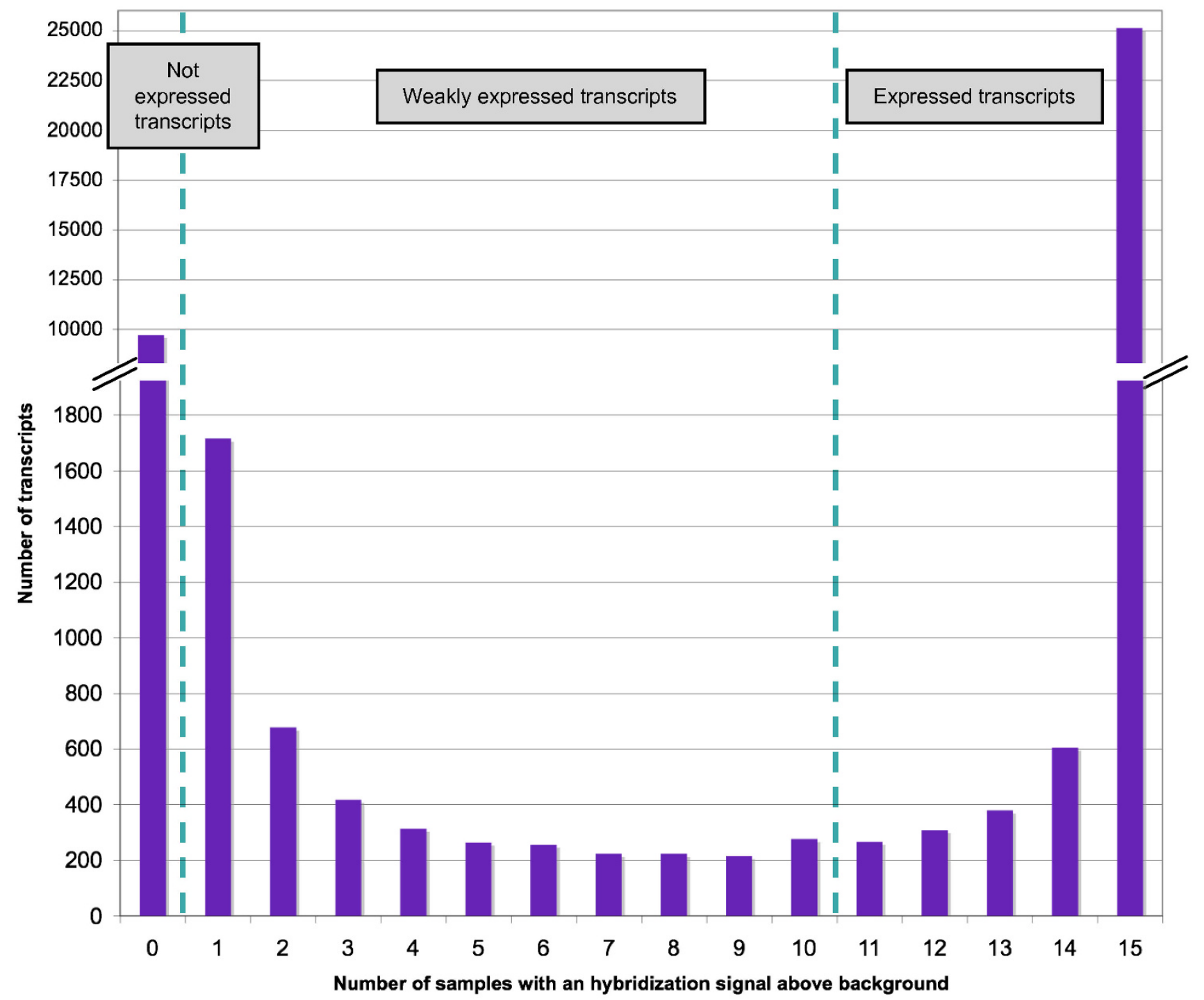

Figure I

Number of features above background. RNA from 15 olfactory epithelia (eight rats were killed, but one olfactory RNA sample did not pass the quality control test (the RIN test) and was not further processed) were hybridized in parallel. The $y$ axis represents the number of transcripts plotted against the number of samples (0 to I5) with a hybridization signal above background levels, as defined by GeneSpring. Transcripts for which II or more of the 15 samples (73\%) gave raw values above background levels were scored as "expressed". Transcripts positive in I to 10 samples were scored as "weakly expressed". All other transcripts were scored as "not expressed".

vidual (either both positive or both negative), and thus clearly expressed by some animals and not expressed by others.

As discussed in more detail below, the set of probes corresponding to weakly expressed or not expressed genes in these experiments depends on the sensitivity of the detection method used. Nevertheless, the proportion of OR genes considered to be expressed at detectable levels in this study is consistent with previous suggestions that up to $76 \%$ of OR genes are expressed at a detectable level in the human olfactory epithelium [10].

- Statistical analysis (t-test)

We performed a statistical analysis (t-test, $p$ value $<0.01$ ) to identify genes that were differentially expressed between animals from two different suppliers and between males and females. 


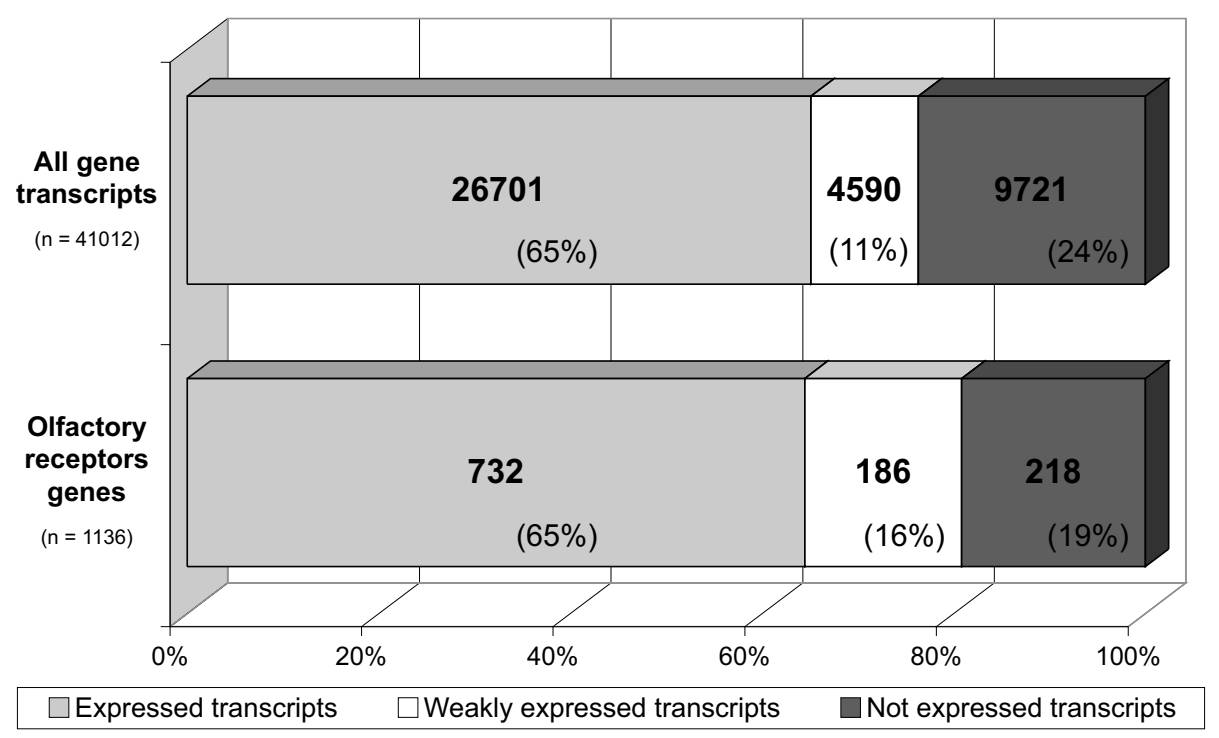

\section{Figure 2}

Expression of gene transcripts and OR transcripts. Grouping of total gene transcripts and OR transcripts into three categories: expressed, weakly expressed and not expressed. For 39,308 of the 4I,0I2 unique probes on the array, an accession number is given in GenBank and Ensembl [45]. They correspond to 23,642 unique transcripts or genes, including II36 OR genes. The ratios of expressed transcripts over not expressed transcripts and of expressed OR genes over not expressed OR genes are 2.75 and 3.36 , respectively.

Only 10 genes, none of which encoded an OR gene, were differentially expressed between rats of the two different origins. These genes were distributed over seven different autosomal chromosomes plus the "Unknown" chromosome [28] (Table 1). Six of these 10 genes were more strongly expressed, with levels twice as high, in the Charles River rats than the Elevage Janvier rats. The other four of these genes were expressed more strongly in rats from Elevage Janvier. One gene, Per3, was identified twice by two independent probes, validating this finding. Per3 and $D b p$, also identified among these ten genes, are both involved in circadian rhythm [29-32].

We then compared gene expression in the olfactory epithelium between males and females. Four genes, none of which encode an OR gene, were found to be expressed more strongly in female olfactory epithelium (expression levels 1.7 times higher; Table 2). Three of these genes are located on the RNOX (Rattus Norvegicus X) chromosome, consistent with their stronger expression in females; the fourth gene is located on RNO2. The Eif $2 s 3 x$ gene (on RNOX) was detected twice, by two independent probes spotted onto the microarrays, again validating the differential expression of this gene. Moreover, two of these four genes, Eif2s $3 x$ and Utx, have previously been reported to be overexpressed in female mouse brain [33-35]. In line with these results, studies on adult Sprague-Dawley rats [36] with Affymetrix pangenomic arrays, or on mice [27] with arrays dedicated to OR and vomeronasal (V1R only) genes have shown no detectable difference in OR gene expression between sexes.

We performed hierarchical clustering and principal component analysis for the whole set of expressed gene transcripts and with OR genes only (data not shown). The absence of clear clustering using either of these two approaches, together with only a very small number of genes identified in the t-test analysis, clearly demonstrates that all animals expressed essentially the same genes to similar levels, regardless of their origin and sex.

- Real-time reverse-transcription PCR analysis (RTqPCR)

Microarray hybridization represents an efficient method of comparing RNA expression levels between samples. However, as the hybridization efficiency and kinetics differ between pairs of targets and probes, it does not provide a good estimate of the relative abundance of mRNA within a sample. To overcome this limitation, we performed RTqPCR with three RNA samples to evaluate the expression level of 77 OR genes selected to represent the entire OR gene repertoire. We also included $G$ olf, the $G$ subunit of OSN [37]. A mean difference of $6.5 \mathrm{Ct}$ was observed between the most and least strongly expressed OR genes, corresponding to a 100-fold difference in transcript levels (Figure 3). A gradual change in mRNA concentration was observed between the highest and lowest amounts of transcript (Figure 3 ). In a previous study, a difference of up to 300-fold between the least and most 
Table I: Genes differentially expressed in the olfactory epithelia of rats from different suppliers

\begin{tabular}{|c|c|c|c|c|c|c|}
\hline Agilent Probe & Gene Symbol & Gene Name & Genbank ID & Chromosome & RGD ID & $\begin{array}{l}\text { Fold difference Charles } \\
\text { River/Janvier }\end{array}$ \\
\hline A_44_P560II3 & - & - & - & RNOI7 & - & 2.542 \\
\hline A_44_P795878 & - & - & - & RNO4 & - & $2.27 \mathrm{I}$ \\
\hline A_43_PI6I43 & Per3 & period homolog 3 & NM 023978 & RNO5 & 621581 & 2.19 \\
\hline A_44_P210809 & Hiatll & $\begin{array}{l}\text { hippocampus abundant transcript- } \\
\text { like I }\end{array}$ & $\underline{X M ~ 225093}$ & RNOI7 & 1308377 & 2.168 \\
\hline A_44_PI96198 & Per3 & period homolog 3 & NM 023978 & RNO5 & 621581 & 2.138 \\
\hline A_44_P900646 & - & - & - & chrUn & - & 2.134 \\
\hline A_44_P280898 & Dbp & $\begin{array}{l}\text { D site of albumin promoter } \\
\text { (albumin D-box) binding protein }\end{array}$ & NM 012543 & RNOI & 2491 & 2.094 \\
\hline A_44_P73954I & - & - & - & RNOI4 & - & 0.412 \\
\hline A_44_P926835 & Rab3gap2 & $\begin{array}{l}\text { RAB3 GTPase activating protein } \\
\text { subunit } 2\end{array}$ & NM 001040154 & RNOI3 & 1311518 & 0.4 \\
\hline A_44_P240696 & Nppc & natriuretic peptide precursor $\mathrm{C}$ & NM 053750 & RNO9 & 620850 & 0.298 \\
\hline A_42_P473398 & Cxcll & chemokine ( $\mathrm{C}-\mathrm{X}-\mathrm{C}$ motif) ligand I & NM 030845 & RNOI4 & 619869 & 0.237 \\
\hline
\end{tabular}

Genes differentially expressed in the olfactory epithelia of rats obtained from two different suppliers and ranked by fold difference. Note that Per3 was identified twice and that four probes correspond to non-annotated genes.

Table 2: Genes differentially expressed in the olfactory epithelia of male and female rats

\begin{tabular}{|c|c|c|c|c|c|c|}
\hline Agilent Probe & Gene Symbol & Gene Name & Genbank ID & Chromosome & RGD ID & $\begin{array}{c}\text { Fold difference } \\
\text { Female/Male }\end{array}$ \\
\hline A_44_PI07I28I & - & - & $\underline{\mathrm{A} 1072660}$ & RNOX & - & 2.846 \\
\hline A_44_P384683 & Utx & $\begin{array}{l}\text { ubiquitously transcribed } \\
\text { tetratricopeptide repeat, } \mathrm{X} \\
\text { chromosome }\end{array}$ & $\underline{X M ~ 228424}$ & RNOX & $|56548|$ & 2.082 \\
\hline A_44_P379924 & Ccdc39 & coiled-coil domain containing 39 & NM 001107667 & RNO2 & 1306277 & 1.869 \\
\hline A_43_PI6682 & Eif2s $3 x$ & $\begin{array}{l}\text { eukaryotic translation initiation } \\
\text { factor } 2 \text {, subunit } 3 \text {, structural gene } \\
\text { X-linked }\end{array}$ & $\underline{X M \quad 216704}$ & RNOX & $156 \mid 279$ & 1.838 \\
\hline A_44_P500598 & Eif2s $3 x$ & $\begin{array}{l}\text { eukaryotic translation initiation } \\
\text { factor } 2 \text {, subunit } 3 \text {, structural gene } \\
\text { X-linked }\end{array}$ & $\underline{X M ~ 216704}$ & RNOX & $156 \mid 279$ & 1.721 \\
\hline
\end{tabular}

Genes differentially expressed in olfactory epithelia between male and female rats Note that Eif2s $3 x$ was identified twice and one probe corresponds to a non-annotated gene. 
strongly expressed mouse OR genes was calculated from the frequency at which OR mRNA clones were obtained [9]. We found a mean difference of 6.2 Ct between Golf and the most strongly expressed OR genes (i.e. Golf mRNA levels 80 times higher; Figure 3). G olf is expressed by all neurons, whereas a particular OR gene is expressed by only a small subset of neurons, estimated to constitute $0.1 \%$ of total OSNs [27]. Therefore, an individual neuron, particularly in the case of OSNs bearing the most strongly expressed OR, may contain more OR than G olf mRNA. However, more copies of OR than Gaolf mRNA per OSN would not be beneficial in terms of efficient signal transduction; rather, the number of Gaolf mRNA copies may differ between OSNs, with more Gaolf present in OSNs expressing larger amounts of receptor. We compared these $\mathrm{Ct}$ values with the microarray results. Most of the OR genes (64 out of 77), marked in green in Figure 3, were identified as expressed genes in microarray experiments. Three OR genes (marked in red) were identified as not expressed and 10 (marked in yellow) were found to be weakly expressed. A small number of the oligonucleotide pairs designed for RTqPCR experiments, corresponding to 15 additional OR genes, failed to amplify their cognate mRNA (data not shown). Eight of them were later shown to be not expressed by the microarray analyses. Altogether, these findings confirm that a majority of OR genes are indeed expressed in the olfactory epithelium, display- ing considerable variation in the range of expression levels detected.

The four endoturbinates making up the olfactory epithelium were dissected individually in one adult rat and the corresponding RNA samples used for RTqPCR analysis with the same set of primers. We found that these $77 \mathrm{OR}$ genes were expressed differently between these four endoturbinates, whereas Gapdh and G olf genes were expressed at similar levels (Figure 4). Up to 26 OR genes were more strongly expressed in endoturbinate II (Figure 4B), whereas the other ORs were more abundant in one of the other three endoturbinates (Figure 4D to 4F). We did not find a correlation between OR families and expression levels in any one endoturbinate. Previous in situ hybridizations with ${ }^{35}$ S-labeled antisense OR RNA probes have shown that neurons expressing individual receptors are topographically localized in different radial zones [1921]. The preferential expression of a number of OR genes in a particular endoturbinate, as shown here, demonstrates another level of complexity in the olfactory epithelium structure and extends our understanding based on previous studies using electro-olfactograms [38].

\section{II - Changes in mRNA profile with aging}

We investigated olfactory epithelium mRNA profiles at various ages, from birth to old age. Four female rats and

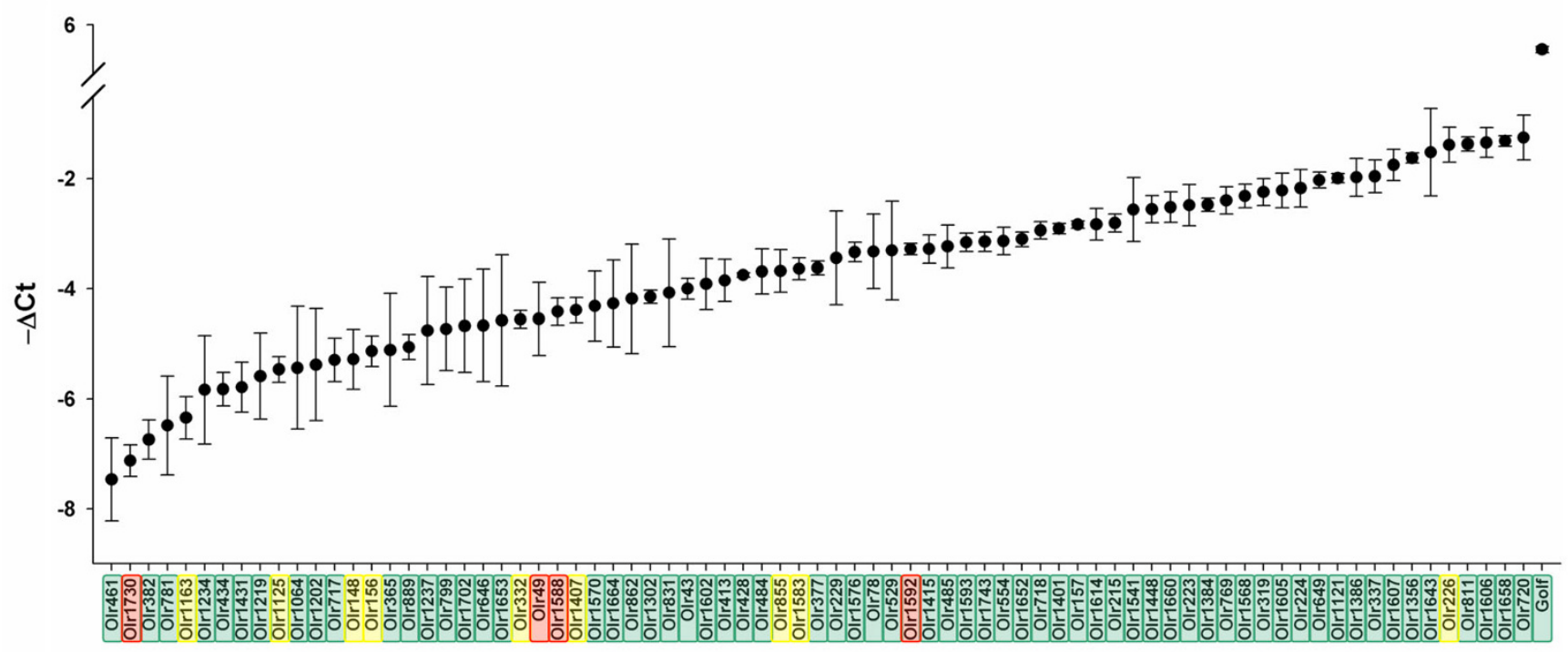

Figure 3

Delta Ct values for 77 OR genes. Results of RTqPCR (means of technical triplicate for each gene), are expressed as delta Ct values (Cycle threshold), using Hprt mRNA as a reference (Ct OR-Ct Hprt). The analyses were performed on three samples and the size of the vertical bars corresponds to the standard deviation. The curve links the mean $\mathrm{Ct}$ values obtained with these three samples. The name of the OR genes are indicated on the $x$ axis: in green are genes identified as expressed, in yellow the OR genes identified as weakly expressed and in red are the OR genes identified as not expressed by microarray hybridization. As indicated by the size of the vertical bars defining the cycle threshold $(\mathrm{Ct})$ values for any given analyzed RNA, the amount of mRNA differs by 0.08 to $2.2 \mathrm{Ct}$ between the three samples. 

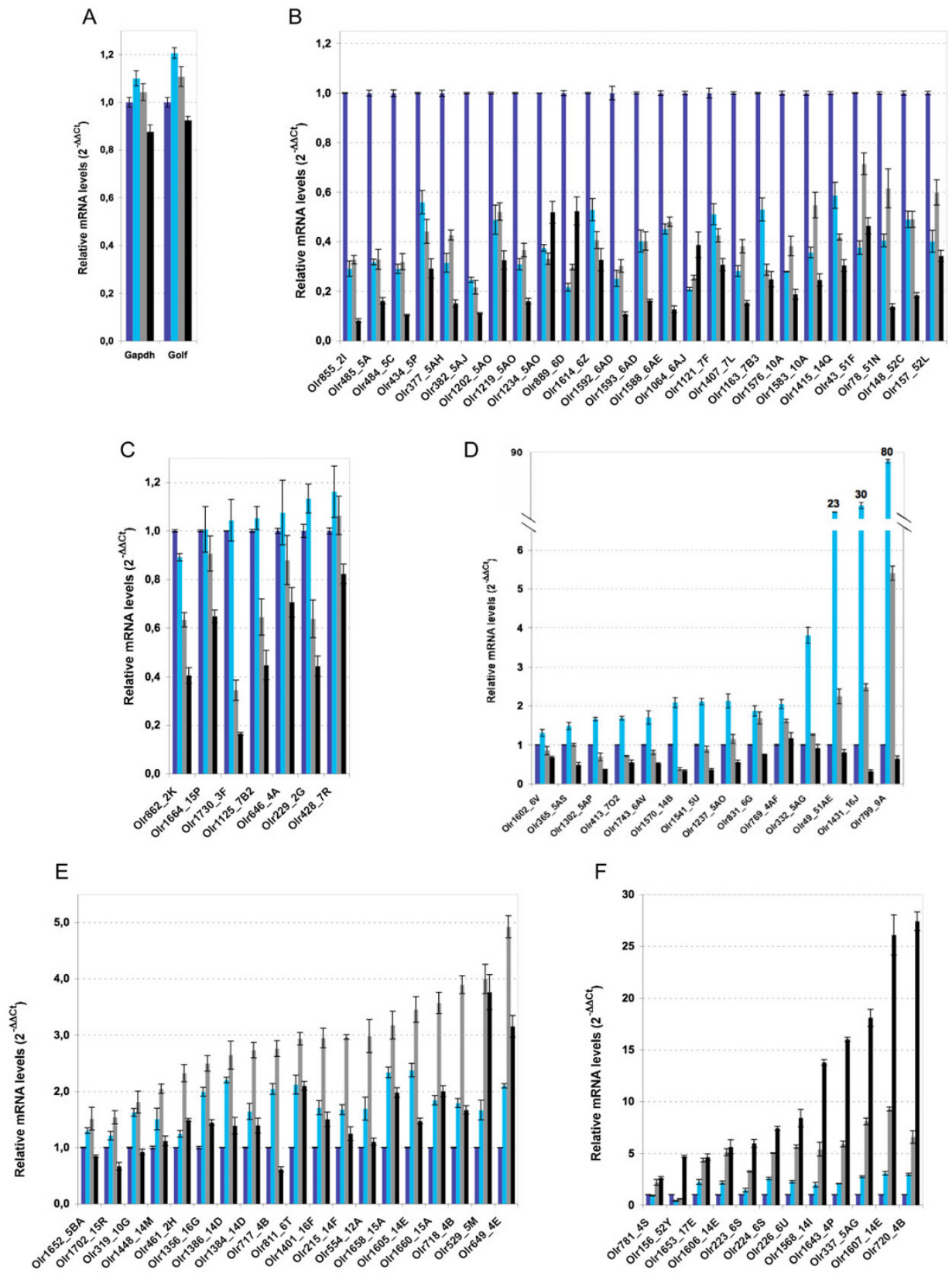

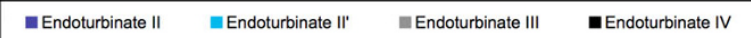

\section{Figure 4}

Differential expression of OR genes in the endoturbinates. We prepared mRNA from the four endoturbinates dissected from an adult rat. mRNA samples were used for RTqPCR (technical triplicates for each gene) for the same set of 77 OR genes. $\Delta \Delta \mathrm{Ct}$ values were expressed with respect to $H$ prt mRNA as internal reference and the control sample as external control as specified in [5I]. Endoturbinate II', III and IV OR Ct values were normalized with respect to endoturbinate II OR Ct values, taken as a reference. The standard deviations are calculated from the triplicate values. Panel $\mathrm{A}$ is a control showing that Gapdh and Golf are expressed at similar levels in the four different endoturbinates. Panel B shows the Ct values for the OR genes that are more strongly expressed in endoturbinate II. Panel $C$ shows OR genes with similar levels of expression in endoturbinates II and II'. In panel D, are shown OR genes more strongly expressed in endoturbinate II'; panel E presents OR genes more strongly expressed in endoturbinate III and, finally, panel F shows OR genes more strongly expressed in endoturbinate IV. On the $x$ axis, OR gene family names follow gene names. 
their newborn pups ( $\mathrm{n}=19 ; 3$ to 5 days old) were purchased. Newborn rats were too small for independent dissection of the right and left sides of the nasal epithelium. Therefore, RNA was extracted from one side only for each pup. RNA was also extracted from the left and right olfactory epithelium of four 22 month-old male rats kept in the animal house from the age of three weeks, and from four nine-week-old male rats. RNA samples were labeled, hybridized and the obtained data were analyzed as described above. The numbers of all transcripts and of OR genes expressed by animals of the three age groups are given in Figure 5. The distribution of expressed, weakly expressed and not expressed transcripts, when all transcripts were taken into account, did not significantly differ between rats of different ages (expressed/not expressed ratios $=2.04$ to 2.45 for newborn, 2.55 for adult (or 2.74, as indicated in Figure 2) and 2.28 for old rats). However, OR gene expression profiles in newborn rats differed from the other two age groups, with "expressed OR"/"not expressed OR" ratios of 0.85 to 1.34 for the four different litters of pups, whereas it was 2.68 for adult (or 3.36 as indicated in Figure 2) and 2.59 for old rats (Mann-Whitney, $p$ value $=0.057$ ).

Comparison of the lists of gene transcripts and OR gene transcripts only showed that a vast majority of them are common to all three age groups. However, there are some notable differences between newborn and the two other groups: 332 OR genes were expressed by adults and older animals but not by newborn rats and nine OR genes were expressed by all newborn rats only (see Venn diagrams in additional file 2). Considering each litter separately, between 15 and 23 OR genes (depending upon the litter)

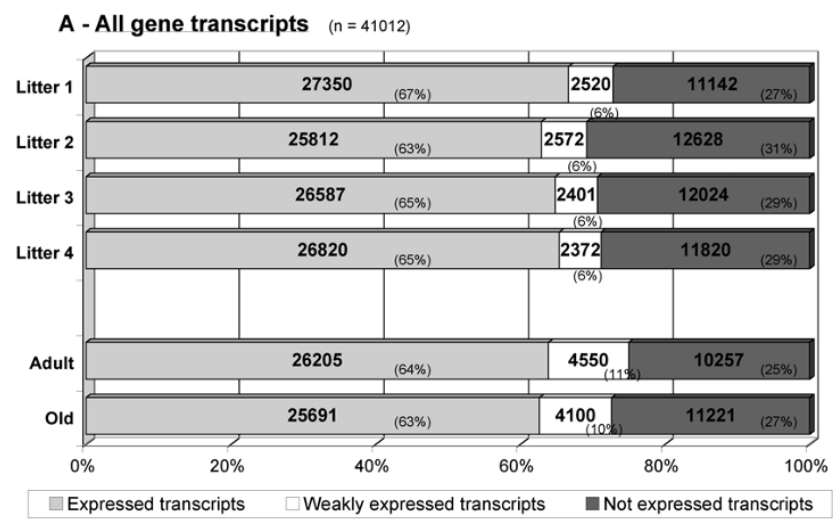

were identified as expressed in newborns only (additional file 3).

We performed RTqPCR for OR genes for which expression was detected only at birth and for which we could design suitable pairs of primers (Figure 6). The results obtained from the four adult rats, four old rats and the 19 newborns displayed large standard deviations, in part due to individual variation but also due to the low level of expression typical of OR genes. Nevertheless, some of these genes tended to be more strongly expressed in pups than in adults or old rats. This effect was particularly marked for Olr500, Olr156 and Olr448. We then selected nine of the 28 OR genes identified as not expressed or very weakly expressed in pups ( $\leq 1$ probe only - out of 19 - with hybridization levels above background) but as being expressed in adults and older rats. RTqPCR data confirmed that they all had a much lower level of expression in pups than in adults or older rats (additional file 4).

The 23,780 transcripts and 393 OR genes expressed by the three age groups were subjected to hierarchical clustering (additional files 5 and 6 and figure 7 ). Well defined clusters were obtained for the three age groups, with high bootstrap values. Principal component analysis (PCA) analysis performed with the same data gave the same result (not shown). This complete separation of the clusters corresponding to the three age groups demonstrated clear differences in the expression levels of the genes expressed by all animals between these groups. We also observed a tendency for pups of the same litter to form clusters when all transcripts were taken into account.

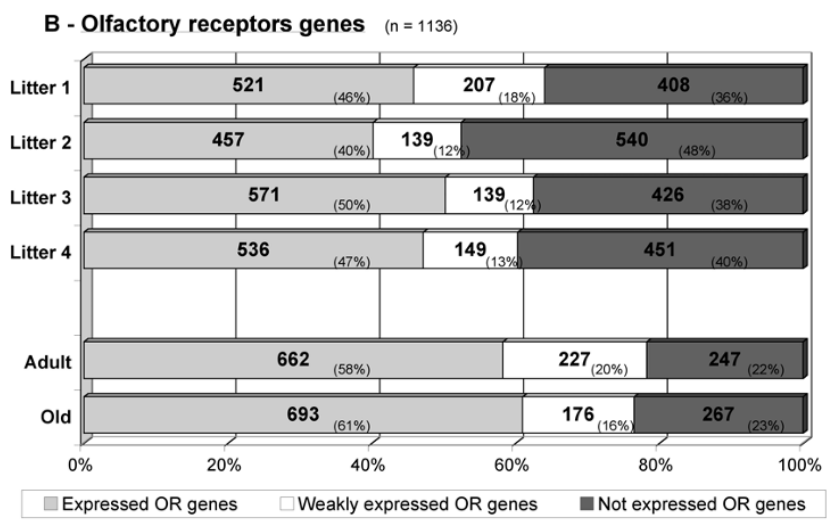

\section{Figure 5}

Expression of gene transcripts and OR transcripts at various ages. Grouping of gene transcripts and OR transcripts into three categories: expressed, weakly expressed and non expressed. In experiments describing adult olfactory epithelium mRNA profiles (Figure I), total transcripts and OR genes were identified as being expressed when $\sim 75 \%$ of the samples gave a corresponding hybridization signal above background levels. Similarly in the experiments described in this figure, we selected as threshold 3 in the case of each litter, 6 for the adults and 6 for the old rats. "Not expressed" total transcripts and "not expressed" OR genes did not show positive signal (above background) for any of the samples. 
However, this clustering effect was far from robust (low bootstrap values) when only OR genes were considered.

We then carried out a statistical analysis of these data (ttest, $\mathrm{p}$ value $<0.01$ ). This showed that $2.0 \%$ of the gene transcripts were differentially expressed, with at least a five-fold difference in mRNA levels between newborns and the two other groups (adult and old animals, Figure 8 ). Only $0.25 \%$ of the transcripts showed differential expression between adult and old rats. Gene ontology (GO) classification analysis of the genes that were up-regulated in newborn rats showed that most of these genes were related to the "Cell Cycle" and "Neurogenesis", whereas the genes up-regulated in adults and old rats were related to the sensory perception of smell. Genes that were less strongly expressed in old rats than in adult rats were classified into GO categories associated with "Developmental processes", "Organ division" and "Ossification" (see also additional file 7 for a complete list of GO terms). Similarly, many OR genes (Figure 8) were identified as less strongly expressed in newborns than in animals of the two other groups, but eight OR genes were found to be overexpressed at birth. Olr1079 and Olr1055 were particularly strongly expressed in all newborns, with transcript levels between 4.6 and 7.7 times higher than in old rats and between 3.2 and 4.8 times higher than in adult rats (Table 3). The expression levels of another OR gene, Olr1119, were found to be higher in all newborns than in adults and, for three of the four litters, than in old rats (Table 3). Three OR genes (Olr336, Olr921 and Olr581) were overexpressed in pups from litters L2 to L4; one OR gene, Olr441, was overexpressed in litters L2 and L3; and another OR gene, Olr995, was overexpressed in litter L3 only.

Next, we performed RTqPCR for the set of the 77 OR genes described above, to compare their expression levels at birth, adulthood and in old age in the olfactory epithelium RNA samples prepared from nine newborn rats from three different litters, three adult rats and three old rats. Box plots (Figure 9) showed that these 77 OR genes have a range of expression levels much greater in newborns than in older animals, and an expression level generally lower in newborns than in adult and old rats. This may be due to the immaturity of the olfactory system in young animals, consistent with the smaller number of OR genes expressed at birth.

Of these 77 OR genes, $43(56 \%)$ were underexpressed at birth (Figure 10C), 29 (38\%) were expressed at similar levels at all ages (Figure 10D) and five (Olr156, Olr382, Olr1163, Olr1219 and Olr1234) were overexpressed at birth (Figure 10B). As these five OR genes were not expressed in all three age groups, they were not included in the t-test analysis. These genes should be added to the list of OR genes that are more strongly expressed at birth.

These findings -- the results of the statistical analysis (ttest; Table 3) identifying eight OR genes more strongly expressed in newborn rats than in adults, the results of RTqPCR, showing five genes overexpressed in newborn rats (Figure 10) and those presented in Figure $6(n=3)$-suggest that a small set of OR genes are more strongly expressed in newborn animals, with the vast majority expressed at a lower level in these animals.

\section{Conclusion}

We report patterns of gene expression in the olfactory epithelium of adult Brown Norway rats. We found that $2 / 3$ of the probes (i.e. 26,701 probes spotted on the arrays) gave a hybridization signal identifying genes expressed at a detectable level. The corresponding genes included 732 OR genes (65\% of the total OR repertoire). We also showed by clustering analysis of the transcripts expressed in common that the pattern of expression depended on the age of the animal rather than on individual characteristics. The number of genes expressed in the olfactory epithelium, whatever their coding function, was found not to differ significantly from those reported for other tissues [39] or from the number of OR genes expressed in the mouse or human olfactory epithelium $[9,10,27]$. However, the classification of a gene as expressed or not expressed depends on both the detection threshold and the analytical methods used. Different arrays made with different probes may give slightly different results, as some genes not detected with one brand of microarrays may be detected by another brand due to different hybridization conditions or probe characteristics. Furthermore high-throughput sequencing, depending upon the sequencing depth, can be expected to extend the list of expressed genes [40]. Extending the list of weakly expressed OR genes is also likely to increase the ratio between the most and least strongly expressed genes.

Extending the list of poorly expressed OR genes will raise many questions. What is the minimum level at which an OR gene must be expressed to induce a signal recognized and processed by the brain? Why are some OR genes strongly expressed, whereas others are expressed only very weakly, if at all? Is this a consequence of the environment or does the panel of expressed OR genes represent the minimum required for the recognition of all relevant odorants, including those not yet encountered? In this case, under what circumstances may the transcription of weakly or not expressed OR genes be up-regulated? Answers to these questions might be obtained by subjecting rats to different olfactory environments. 

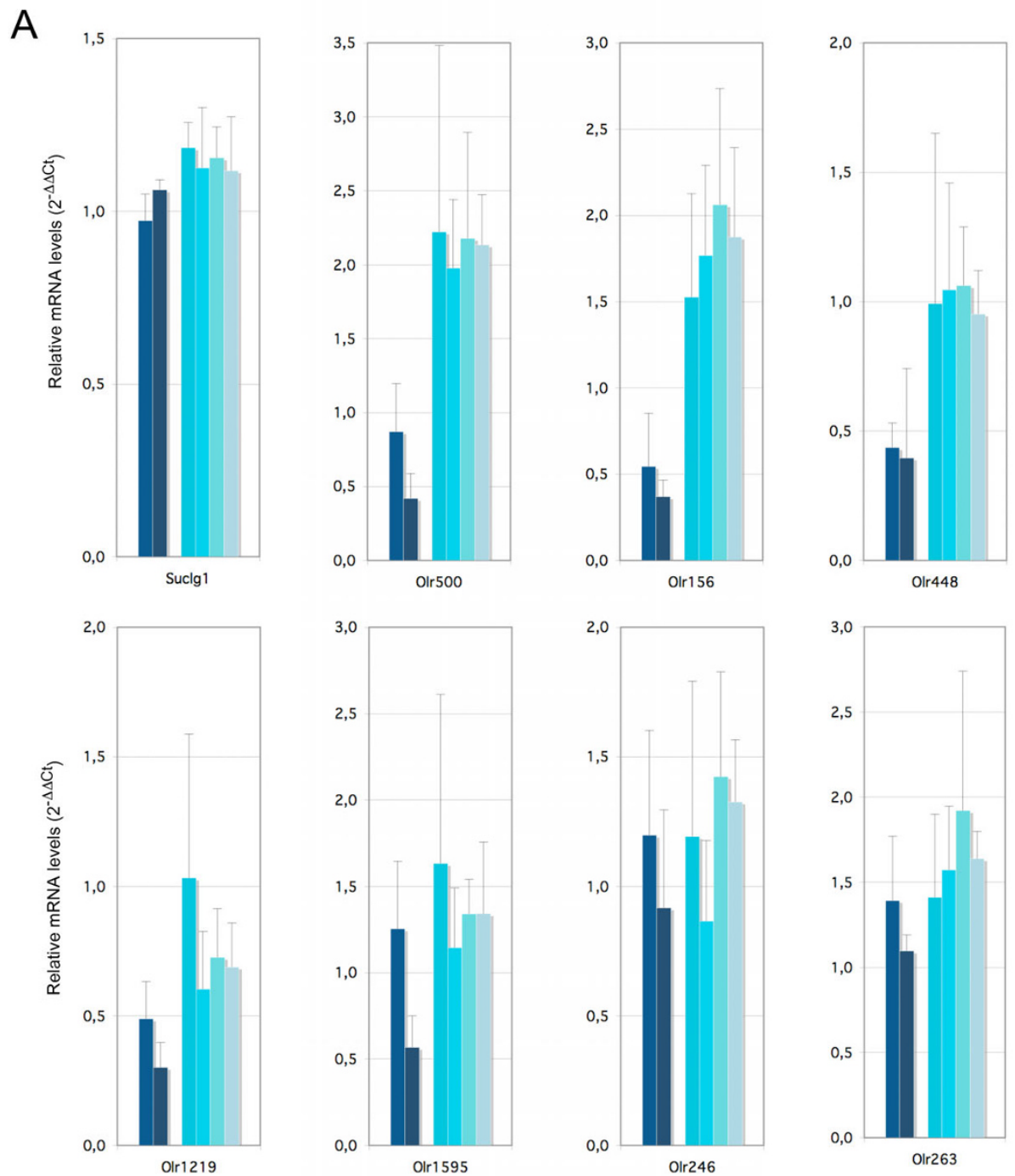

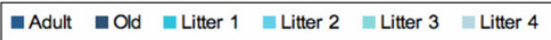

$\mathrm{B}$

\begin{tabular}{|c|c|c|c|c|c|c|c|c|}
\cline { 2 - 9 } \multicolumn{1}{c|}{} & Suclg1 & OIr500 & Olr156 & Olr448 & Olr1219 & OIr1595 & OIr246 & OIr263 \\
\hline Adult $(n=8)$ & $\mathbf{8}$ & 0 & 0 & 4 & 3 & 3 & 3 & 4 \\
\hline Old $(n=8)$ & $\mathbf{8}$ & 0 & 0 & 4 & 0 & 1 & 5 & 3 \\
\hline Litter 1 $(n=4)$ & 4 & 3 & 2 & 4 & 4 & 3 & 3 & 3 \\
\hline Litter 2 $(n=5)$ & 5 & 5 & 5 & 5 & 3 & 5 & 4 & 3 \\
\hline Litter 3 $(n=5)$ & 5 & 5 & 4 & 5 & 5 & 5 & 5 & 5 \\
\hline Litter 4 $(n=5)$ & 5 & 5 & 4 & 5 & 5 & 5 & \\
\hline
\end{tabular}

\section{Figure 6}

Expression levels of OR genes expressed at birth but not in older rats. (A) RNA samples prepared from olfactory epithelia ( 4 adults, 4 old rats and 19 newborns from each litter LI to L4) were used for RTqPCR of 7 OR genes identified by microarray analysis as expressed in newborns only. Each mRNA was analyzed in triplicate and a mean value calculated. $\Delta \mathrm{Ct}$ values were calculated with respect to the $H$ prt values and $\Delta \Delta \mathrm{Ct}$ with respect to a control sample equated to $\mathrm{I}$. Further, the analyses were performed on four samples of the same group of age; error bars represent means $\pm S D$ ( $n=4$ rat RNA samples per group). (B) The table shows the number of samples giving a hybridization signal above background. For Olr500, taken as an example, none of the 8 adult and 8 old rat samples gave a hybridization signal above background. Conversely, all samples from the 15 newborn rats from litters L2 to L4 and three newborn rats of the four of litter LI gave a hybridization signal above background. 


\section{Expressed olfactory receptor genes}
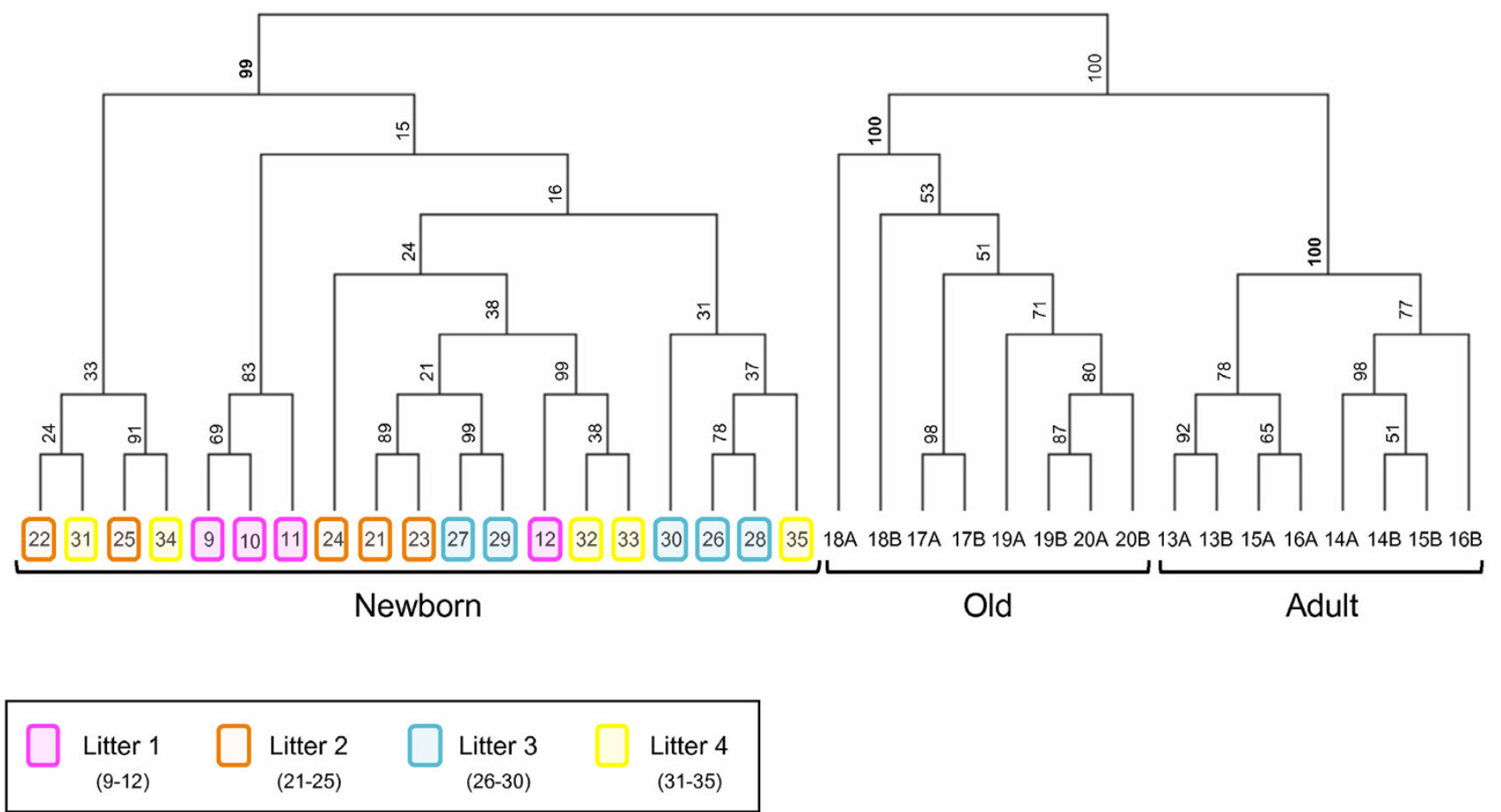

\section{Figure 7}

Hierarchical clustering of samples for OR genes expressed in olfactory epithelium in the three age groups of rats. Numbers at the nodes (range $=I$ to 100 ) indicate support (bootstrap value) for the clustering. Note the high bootstrap values at each node corresponding to the age groups but their much lower values for the downstream branches.

Little difference was found between the olfactory epithelium mRNA profiles of individual Brown Norway adult rats of the same age, sex and origin, allowing a reference transcriptome to be defined. However, the RNA profiles of newborn, adult and old rats showed marked differences: both the lists of genes specifically expressed at each age group and the levels of expression of genes expressed in all three age groups differed between the three groups, allowing a clear clustering of the samples as a function of age.
Although 22-month old rats may not be considered very old, it should be noted that the life expectancy of male Brown Norway rats is only around 31 months [41]. The gradual loss of olfactory responses in old age is probably at least in part due to the loss of central brain function $[42,43]$. However, the small but measurable changes in the mRNA profiles of the olfactory epithelium observed in this study between adults and old rats may also contribute to this deterioration. The smaller number of OR genes

Table 3: OR genes upregulated in newborns

\begin{tabular}{|c|c|c|c|c|c|c|c|c|c|c|}
\hline $\begin{array}{c}\text { Gene } \\
\text { Symbol }\end{array}$ & $\begin{array}{c}\text { Familyl } \\
\text { Subfamily }\end{array}$ & $\begin{array}{l}\text { LI vs } \\
\text { Adult }\end{array}$ & LI vs Old & $\begin{array}{l}\text { L2 vs } \\
\text { Adult }\end{array}$ & L2 vs Old & $\begin{array}{l}\text { L3 vs } \\
\text { Adult }\end{array}$ & L3 vs Old & $\begin{array}{l}\text { L4 vs } \\
\text { Adult }\end{array}$ & L4 vs Old & $\begin{array}{l}\text { Adult vs } \\
\text { Old }\end{array}$ \\
\hline Olrl 079 & $7 A$ & 3.2 & 6.1 & 3.9 & 7.3 & 4.1 & 7.7 & 3.6 & 6.8 & - \\
\hline Olrl 055 & $6 \mathrm{AO}$ & 3.7 & 4.6 & 3.8 & 4.7 & 4.8 & 6.0 & 4.2 & 5.2 & - \\
\hline OlrIII9 & 7B4 & 3.0 & - & 2.9 & 2.9 & 4.4 & 4.4 & 3.9 & 3.9 & - \\
\hline Olr336 & $5 \mathrm{AF}$ & - & - & 2.7 & 2.7 & 2.1 & 2.2 & 2.1 & 2.1 & - \\
\hline Olr92I & $6 \mathrm{D}$ & - & - & 3.2 & 5.4 & 3.4 & 5.8 & 2.5 & 4.3 & - \\
\hline Olr58I & 50 & - & - & 3.5 & 2.4 & 3.7 & 2.4 & 3.0 & - & - \\
\hline Olr44I & $5 F$ & - & - & 2.1 & 2.0 & 2.6 & 2.5 & - & - & - \\
\hline Olr995 & $6 \mathrm{D}$ & - & - & - & - & 2.3 & 2.2 & - & - & - \\
\hline
\end{tabular}

List of OR genes found to be up-regulated in newborn rats by t-test analysis ( $p$ value $<0.0 \mathrm{I}$ ). Fold differences are expressed with respect to adults and old rats. Figures in bold pointed to fold differences $>5$ and "-" mean that the t-test analysis gave no significant $p$ value. 


\section{A - All gene transcripts}

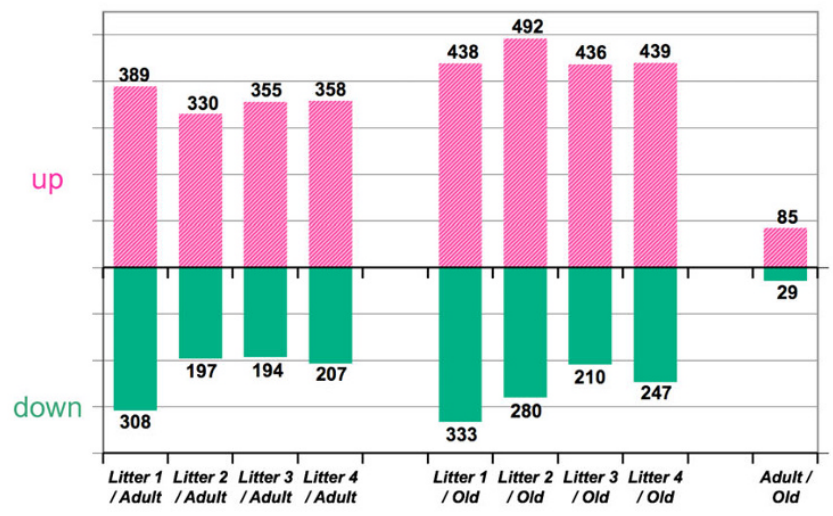

B - Olfactory receptor genes

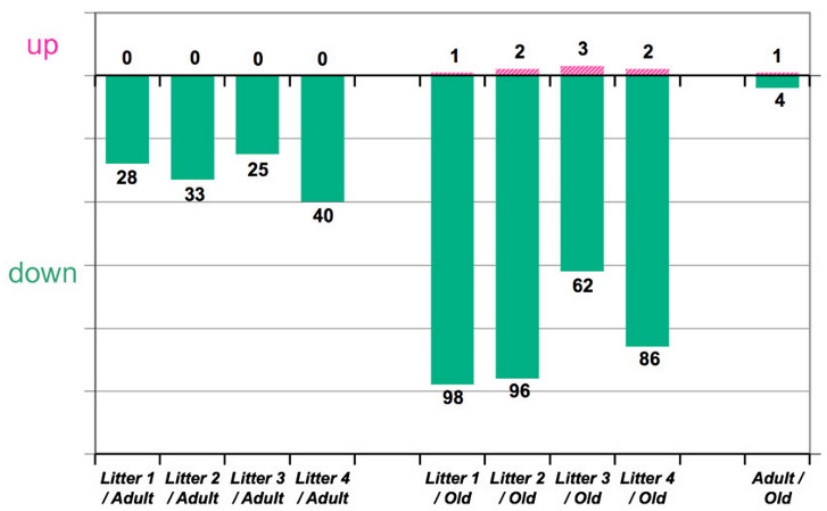

Figure 8

Up- and down-regulated transcripts and OR genes. Numbers of up- and down-regulated transcripts and OR genes (fold change $\geq 5$ ) identified by pair-wise comparisons between age groups.

expressed and their lower levels of expression at birth would be consistent with an incomplete development of olfactory function at this age.

The Venn diagrams, t-tests and RTqPCR analyses reported here all indicate that a small number of OR genes $(n=16)$ were more strongly expressed or expressed exclusively in newborn rats from different litters. This number is likely to be an underestimation considering that five of the 77 OR genes taken at random were overexpressed at birth. The types of ligand they recognize are not known, but given that two- to five-day-old rats are blind and deaf, these OR genes may be important for behavior, motherpup relationship and/or nipple recognition. These findings are consistent with the recent observation that newborn rats react to odorant exposure [44].

\section{Methods}

\section{Animals}

Brown Norway rats were obtained from Charles River Laboratories (L'Arbresle, France) or Elevage Janvier (Le Genest-Saint-Isle, France). Female rats with their progeny (3 to 5 days old) were purchased from Charles River Laboratories. From their arrival until the time at which they were killed, the rats were kept in the animal house (12:12 $\mathrm{h}$ light/dark cycles with free access to food and water) under the rules established by the Board of the Ethical Committee.

\section{Olfactory epithelium dissection}

Rats were anesthetized with an injection of $0.3 \mathrm{ml} / 100 \mathrm{~g}$ body weight ketamine hydrochloride (Clorketam 1000 from Vetoquinol). They were then killed by decapitation. Rat skulls were opened through a sagittal section and right and left olfactory epithelia were quickly removed and placed separately in RA1 Buffer from the Nucleospin RNA II kit (Macherey-Nagel, Düren, Germany).

\section{RNA isolation}

Total RNA was isolated with the Nucleospin RNA kit, according to the manufacturer's (Macherey-Nagel, Düren, Germany) instructions, which included an in-column DNase treatment before RNA elution, to ensure the absence of genomic DNA. Recovered RNA was quantified with a Nanodrop ND-1000 spectrophotometer (NanoDrop Technologies, Cambridge, UK), and RNA integrity was assessed with the RNA 6000 Nano LabChip kit, using the Agilent 2100 Bioanalyzer (Agilent Technologies, Palo Alto CA, USA). Only RNA samples with an RNA Integrity Number (RIN) greater than 8.8 were used for further analysis (RNA profiling analysis and real time reverse transcription PCR analysis). Application of this strict quality threshold resulted in the elimination of the left sample from one male adult rat from Elevage Janvier.

\section{Target preparation and microarray hybridization}

RNA samples were labeled with the Agilent Low RNA Input Fluorescent Linear Amplification kit (p/n 51843523), according to the manufacturer's instructions. Briefly, $350 \mathrm{ng}$ of total RNA was used as template for reverse transcription to generate cDNA, which was transcribed with T7-polymerase; cyanine-3 (Cy3)-labeled CTP was used for labeling. Cy3 labeling was monitored with a Nanodrop ND-1000 spectrophotometer and was found to be between 1.2 and $1.9 \mathrm{pmol} / \mu \mathrm{l}$.

Hybridization was performed with the Agilent Gene Expression Hybridization kit (p/n 5188-5242), used according to the manufacturer's instructions. Briefly, 1650 ng of labeled cRNA from each RNA sample was mixed 


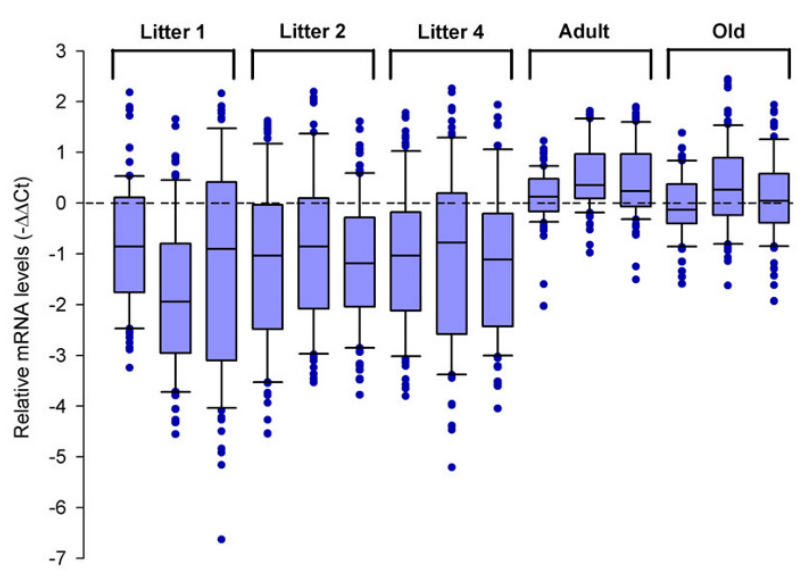

Figure 9

Box plots of RTqPCR data. The RTqPCR results detailed in Figure 10 are presented as box plots. Note the lower positions of the medians for the newborn samples and the greater dispersion of $\Delta \Delta \mathrm{Ct}$ values. A Mann-Whitney test performed with the 77 values calculated for the different samples confirmed that the data obtained for newborns differed from those obtained for the old and adult groups ( $p$ values $\left.<10^{-10}\right)$.

with Hybridization Buffer and Blocking Agent and subjected to fragmentation (by incubation for $30 \mathrm{~min}$ at $60^{\circ} \mathrm{C}$ in the dark). Hybridizations onto $4 \times 44 \mathrm{~K}$ Whole Rat Genome 60-mer oligonucleotide microarrays (G4131F) (Agilent Technologies, Palo Alto CA, USA) were performed in a rotary oven $\left(65^{\circ} \mathrm{C}, 17 \mathrm{~h}\right.$ and $\left.10 \mathrm{rpm}\right)$ in the dark. Slides were disassembled and washed in Gene Expression Wash Buffers I and II, according to the manufacturer's instructions, and dried with a nitrogen-filled air gun before scanning. Fifteen arrays were used for the experiment analyzing the male/female and rat origin comparisons. Thirty-five arrays were used for the "aging" comparison.

\section{Data acquisition and processing}

Microarrays were scanned with a dynamic autofocus microarray scanner (Agilent DNA Microarray Scanner), using Agilent parameters. Feature Extraction software version 9.5 was used to extract and analyze the signals. Array results were analyzed with GeneSpring GX software version 7.3 (Agilent Technologies), via the Enhanced Agilent Feature Extraction Import Preprocessor.

Data were normalized in two steps, using the algorithms supplied with the Feature Extraction software. Data were first transformed to convert any negative value to 0.01 ; normalization was then performed by a per-chip $50^{\text {th }}$ percentile method, which normalized the data for each chip with respect to the median of the chip concerned, allow- ing comparison between chips. A second normalization step was applied to the results for each gene across all the arrays in the study ("normalize to median"): the median of all the values obtained for a given gene was calculated and used as the normalization standard for that gene, such that, regardless of absolute differences in the expression of the various genes, all were placed on the same scale for comparison.

The accuracy of microarray results was assessed by comparing the overall gene expression levels for each chip by box plot analysis. Each box plot was centered on zero, with comparable dynamic intensities, demonstrating the technical homogeneity of the experiment overall (data not shown).

The microarray data have been uploaded into the Gene Expression Omnibus (GEO) database (SuperSeries no. GSE15954 and samples nos. GSM400094-GSM400143).

\section{Expressed transcripts}

Low-intensity and unreliable results were removed using a "filter on flags" feature, with standardized software algorithms classifying spots as "present," "marginal," or "absent". Spots were considered "present" only if the output was uniform, not saturated and significantly above background; spots that satisfied the main requirements but were outliers relative to the typical values for the other genes were considered "marginal". Filters were set to retain for further analysis only those values classified as "present" or "marginal".

The terms "present" or "marginal" defining the nature of the hybridization signals on each microarray should not be confused with the terms expressed transcripts, weakly expressed transcripts and not expressed transcripts defined by comparing the results obtained with the different samples, as explained in Figure 1.

\section{Content of the $44 \mathrm{~K}$ Agilent microarrays}

There are currently 44,012 probes on each microarrays. By annotation assignments [45], accession numbers could be assigned to 39,308 of the 39,688 probes for which the manufacturer provided chromosomal location information: rat GenBank accession numbers were assigned for 36,383 of the probes; rat Ensembl transcript identifications (IDs) were assigned for 168 other probes; and nonrat accession numbers for 2,757 probes for which no rat annotations were available. Together, these probes encompass 23,642 unique rat accession numbers and 2,270 unique non-rat accession numbers and represent 16,947 rat Unigene IDs plus 5,941 non-rat Unigene IDs (Unigene build 166). In addition to these probes, there are a number of so-called technical probes engineered by Agilent and used by GeneSpring to ascertain the quality of 


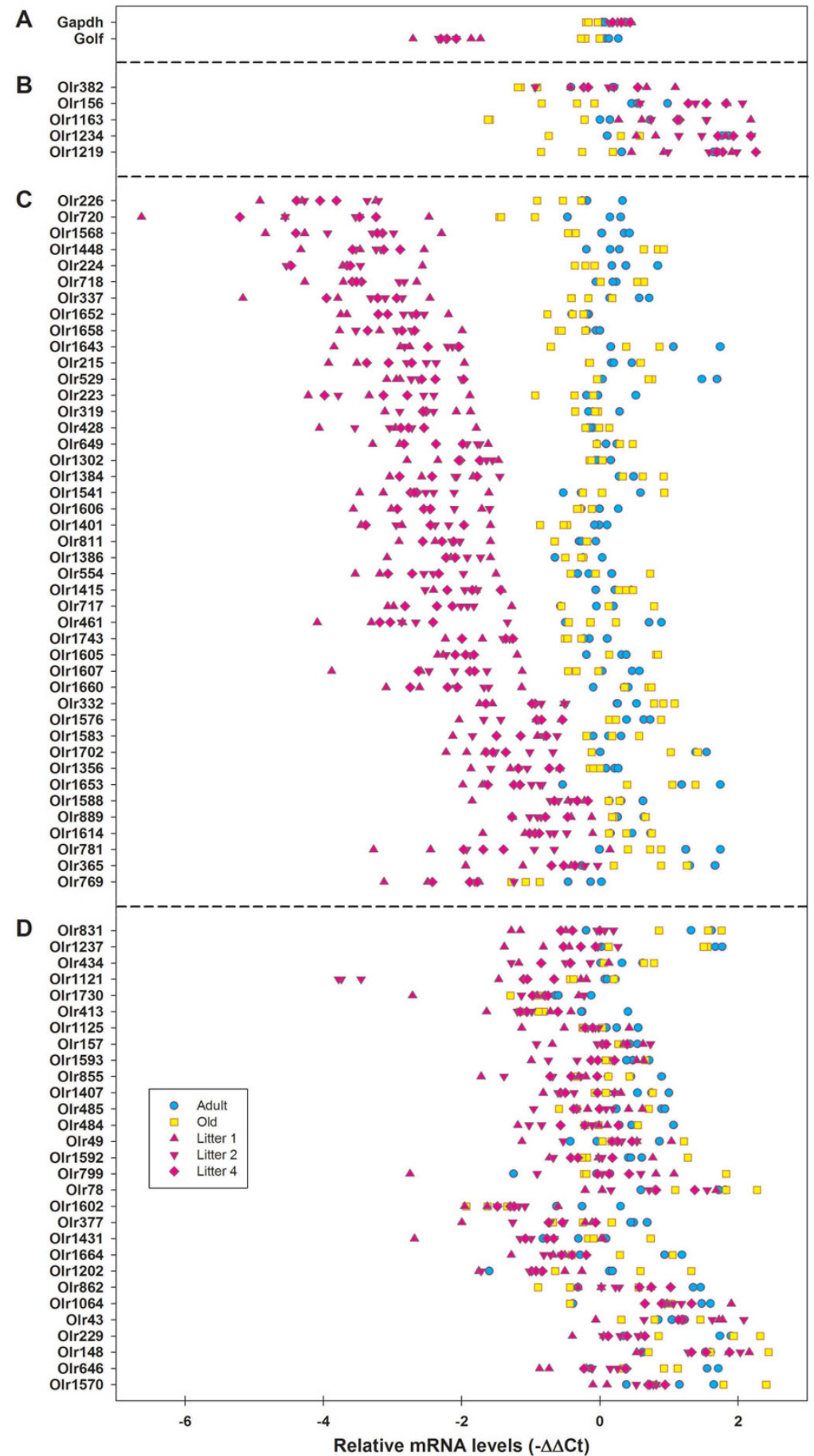

\section{Figure 10}

Relative expression of a subset of 77 OR genes at three different ages. RTqPCR was performed for 77 OR mRNAs, with olfactory epithelium mRNA prepared from 3 adult rats, 3 old rats and 9 newborn rats from three litters (LI, L2 and L4) used as a template (i.e. 15 samples, each analyzed in triplicate). Results are expressed as $\Delta \Delta \mathrm{Ct}$ values with $H$ prt taken as a reference ( $x$ axis). Gene names are distributed into four sectors, from top to bottom: $(A) G$ olf, which is clearly less strongly expressed at birth and Gapdh, which is expressed at similar levels in all age groups, (B) 5 OR genes more strongly expressed at birth than later in life, (C) 43 OR genes far less strongly expressed at birth than at other ages and (D) 29 genes expressed to a similar extent at birth and at other ages or only slightly less strongly expressed at birth. 
the data. For additional details, please consult the Agilent website [46].

Due to uncertainties regarding the names of a number of genes that are probed by many oligonucleotides on the arrays, the term "gene transcripts", used throughout this paper, designates transcripts and genes collectively identified by these probes, except for OR genes that are annotated as such. Although some gene transcripts were probed by more than one oligonucleotide, each OR gene was probed by a single oligonucleotide.

\section{Selection of differentially expressed genes}

We performed t-test analysis with GeneSpring software (Benjamini \& Hochberg correction for false discovery rate ( $p$ value of 0.01$)$ ) to select genes that were differentially expressed between groups.

\section{Hierarchical clustering}

Hierarchical support trees including bootstrap analysis with replacement after 1000 iterations were constructed with TIGR Mev v 4.2 software [47]. Numbers at the nodes (range $=1$ to 100 ) indicate the support for the clustering. The clustering pattern was generated by Pearson Correlation with average linkage clustering.

\section{Functional annotation}

Analysis of the enrichment of expressed genes with Gene Ontology (GO) categories (i.e. GO terms with a significantly larger number of associated genes than expected for a random distribution) was performed with NIH DAVID $[48,49]$. Briefly, the GenBank accession numbers of the genes of interest were uploaded to the DAVID website and analysis was carried out with the Rattus norvegicus gene repertoire as a reference list. GO categories with significantly larger numbers of expressed genes than expected ( $p$ value corrected $<0.05$ ) were selected.

\section{Real time reverse transcription PCR analysis (RTqPCR)}

RTqPCR was performed for a number of genes, with forward (F) and reverse (R) primers designed with Primer3 software [50] (additional file 8). Primer specificity was assessed from the monophase dissociation curves. Only pairs presenting similar efficiencies $(100 \pm 5 \%)$ were retained (data not shown). Briefly, the High-Capacity cDNA Archive kit (Applied Biosystems, Foster City, CA, USA) was used for reverse transcription and the Power SYBR Green PCR master kit (Applied Biosystems) was used for quantitative PCR, according to Applied Biosystems gene amplification specifications ( 40 cycles of $15 \mathrm{~s}$ at $95^{\circ} \mathrm{C}$ and $1 \mathrm{~min}$ at $60^{\circ} \mathrm{C}$ ). Gene expression was analyzed with the ABI Prism 7900HT sequence detection system, and results were handled with the associated SDS version 2.3 software (Applied Biosystems).
Hprt (hypoxanthine-guanine phosphoribosyltransferase) mRNA levels did not vary significantly between groups or experiments. This gene was therefore used as an internal reference for the comparison of rats of different origins and ages. The relative amounts of gene transcripts were determined by the Ct method [51]. Each PCR was carried out in triplicate. Results from different samples were compared to a "control sample" corresponding to RNA prepared from one adult rat epithelium.

\section{List of abbreviations used}

Cy: cyanine; DNA: deoxyribonucleic acid; GEO: Gene Expression Omnibus; GO: Gene Ontology; OR: olfactory receptor; OSN: olfactory sensory neuron; PCA: principal component analysis; PCR: polymerase chain reaction; RIN: RNA integrity number; RNA: ribonucleic acid; RT: reverse transcription; $\mathrm{SD}$ : standard deviation

\section{Authors' contributions}

MR carried out molecular genetic experiments, interpreted the data and drafted the manuscript. SR carried out molecular genetic experiments. AV participated in the statistical treatment of the data. FG conceived, designed, coordinated the study and helped write the manuscript. All authors read and approved the final manuscript.

\section{Additional material}

\section{Additional file 1}

List of the 1136 OR genes that are probed in the 44K Agilent microarray. This XLS document contains a list of the 1136 OR genes that are probed in the $44 \mathrm{~K}$ Agilent microarray.

Click here for file

[http://www.biomedcentral.com/content/supplementary/14712164-10-572-S1.XLS]

\section{Additional file 2}

Venn diagrams of transcripts and OR genes expressed in rats of the different groups of age. This PDF document displays Venn diagrams of transcripts and OR genes expressed in rats of the different groups of age. Click here for file

[http://www.biomedcentral.com/content/supplementary/14712164-10-572-S2.PDF]

\section{Additional file 3}

Venn diagrams of OR genes expressed in newborn rats. (A) Numbers of expressed OR genes, deduced by microarray hybridization of the RNA samples prepared from newborns of four different litters compared to the $O R$ genes expressed by adults and old rats. (B) Names of OR genes expressed in all newborn rats but not in adults and old rats. Comparisons of the OR genes expressed in each litter with the other two age groups showed that 15 to 23 OR genes per litter were expressed exclusively in newborn rats. Interestingly, 9 of these OR genes were identified in newborn rats from all litters, four OR genes in litters L2, L3 and L4 and two OR genes in litters L1, L3 and L4. This suggests that newborn animals express a characteristic set of OR genes that is not expressed in older rats. Click here for file

[http://www.biomedcentral.com/content/supplementary/14712164-10-572-S3.PDF] 


\section{Additional file 4}

mRNA levels of nine OR genes identified by microarray as expressed in adult and old animals but not in newborns. Diagram showing RTqPCR results for nine OR genes randomly selected from the $28 \mathrm{OR}$ genes not expressed at birth but expressed in adult and old animals; Suclg1, which was found on microarray analysis to be expressed to a similar extent in all the age groups tested, was used as a control in this experiment. Each mRNA was analyzed in triplicate and a mean value calculated. Ct values were calculated with respect to the Hprt values and $C t$ with respect to a control sample equated to 1 . Further, the analyses were performed on four samples of the same group of age; error bars represent means $\pm S D(n=4$ rat $R N A$ samples per group $)$.

Click here for file

[http://www.biomedcentral.com/content/supplementary/14712164-10-572-S4.PDF]

\section{Additional file 5}

Hierarchical clustering of samples using all transcripts for which mRNA was detected in all three groups of age. Numbers at the nodes (range $=1$ to 100) indicate support (bootstrap value) for the clustering. Click here for file

[http://www.biomedcentral.com/content/supplementary/1471-

2164-10-572-S5.PDF]

\section{Additional file 6}

Comparison of expression level between and within age groups. These two figures illustrate the close level of mRNA expression observed between samples prepared from animals of the same group of ages. Figure A: the microarray expression levels of three OR $m R N A$ taken at random are compared between the 19 pup samples from 4 litters, 8 samples from 4 adults and 8 samples from 4 old rats. Figure B is a color code hierarchical clustering representation of the profiles of the 393 OR mRNA expressed in common (see additional file 2) within the 35 samples prepared from newborn, adult and old rats.

Click here for file

[http://www.biomedcentral.com/content/supplementary/14712164-10-572-S6.PDF]

\section{Additional file 7}

GO terms characterizing the transcripts and OR genes up- or downregulated in the three different age groups. Differentially expressed genes: Newborn/Old rats (up-expressed in newborn rats/foldchange $>=$ 5)

Click here for file

[http://www.biomedcentral.com/content/supplementary/14712164-10-572-S7.XLS]

\section{Additional file 8}

Oligonucleotides used for RTqPCR. This XLS file contains Oligonucleotides used for RTqPCR.

Click here for file

[http://www.biomedcentral.com/content/supplementary/14712164-10-572-S8.XLS]

\section{Acknowledgements}

The Centre National de la Recherche Scientifique, the Université de Rennes I, the Conseil Régional de Bretagne and the Technical Support Working Group (TSWG) are thanked for their generous support and encouragement to FG. The authors are grateful to the referees for their constructive comments.

\section{References}

I. Buck L, Axel R: A novel multigene family may encode odorant receptors: a molecular basis for odor recognition. Cell I99I, 65(1): $175-187$.

2. Olender T, Lancet D, Nebert DW: Update on the olfactory receptor (OR) gene superfamily. Hum Genomics 2008, 3(1):87-97.

3. Niimura $Y$, Nei M: Extensive gains and losses of olfactory receptor genes in Mammalian evolution. PLoS One 2007, 2(I):e708.

4. Quignon P, Giraud M, Rimbault M, Lavigne P, Tacher S, Morin E, Retout E, Valin AS, Lindblad-Toh K, Nicolas J, et al.: The dog and rat olfactory receptor repertoires. Genome Biol 2005, 6(I 0):R83.

5. Malnic B, Godfrey PA, Buck LB: The human olfactory receptor gene family. Proc Natl Acad Sci USA 2004, I 0 I (8):2584-2589.

6. Godfrey PA, Malnic B, Buck LB: The mouse olfactory receptor gene family. Proc Natl Acad Sci USA 2004, 10 I(7):2156-2I6I.

7. Robin S, Tacher S, Rimbault M, Vaysse A, Dreano S, Andre C, Hitte $\mathrm{C}$, Galibert F: Genetic diversity of canine olfactory receptors. BMC Genomics 2009, 10:21.

8. Menashe I, Man O, Lancet D, Gilad Y: Different noses for different people. Nat Genet 2003, 34(2): I 43-144.

9. Young JM, Shykind BM, Lane RP, Tonnes-Priddy L, Ross JA, Walker M, Williams EM, Trask BJ: Odorant receptor expressed sequence tags demonstrate olfactory expression of over $\mathbf{4 0 0}$ genes, extensive alternate splicing and unequal expression levels. Genome Biol 2003, 4(I I):R7I.

10. Zhang X, De la Cruz O, Pinto JM, Nicolae D, Firestein S, Gilad Y: Characterizing the expression of the human olfactory receptor gene family using a novel DNA microarray. Genome Biol 2007, 8(5):R86.

II. Feldmesser E, Olender T, Khen M, Yanai I, Ophir R, Lancet D: Widespread ectopic expression of olfactory receptor genes. $B M C$ Genomics 2006, 7:121.

12. Pluznick JL, Zou DJ, Zhang X, Yan Q, Rodriguez-Gil DJ, Eisner C, Wells E, Greer CA, Wang T, Firestein S, et al.: Functional expression of the olfactory signaling system in the kidney. Proc Nat Acad Sci USA 2009, 106(6):2059-2064.

13. Firestein S: How the olfactory system makes sense of scents. Nature 200I, 4I3(6852):2II-2I 8 .

14. Chess A, Simon I, Cedar H, Axel R: Allelic inactivation regulates olfactory receptor gene expression. Cell 1994, 78(5):823-834.

15. Malnic B, Hirono J, Sato T, Buck LB: Combinatorial receptor codes for odors. Cell 1999, 96(5):713-723.

16. Ishii T, Serizawa S, Kohda A, Nakatani H, Shiroishi T, Okumura K, Iwakura Y, Nagawa F, Tsuboi A, Sakano H: Monoallelic expression of the odourant receptor gene and axonal projection of olfactory sensory neurones. Genes Cells 200I, 6(I):7I-78.

17. Serizawa S, Ishii T, Nakatani H, Tsuboi A, Nagawa F, Asano M, Sudo $\mathrm{K}$, Sakagami J, Sakano H, ljiri T, et al:: Mutually exclusive expression of odorant receptor transgenes. Nat Neurosci 2000 , 3(7):687-693.

18. Serizawa S, Miyamichi K, Nakatani H, Suzuki M, Saito M, Yoshihara Y, Sakano $\mathrm{H}$ : Negative feedback regulation ensures the one receptor-one olfactory neuron rule in mouse. Science 2003 , 302(5653):2088-2094.

19. Ressler KJ, Sullivan SL, Buck LB: A zonal organization of odorant receptor gene expression in the olfactory epithelium. Cell 1993, 73(3):597-609.

20. Vassar R, Ngai J, Axel R: Spatial segregation of odorant receptor expression in the mammalian olfactory epithelium. Cell 1993, 74(2):309-318.

21. Mombaerts P, Wang F, Dulac C, Chao SK, Nemes A, Mendelsohn M, Edmondson J, Axel R: Visualizing an olfactory sensory map. Cell 1996, 87(4):675-686.

22. Barnea G, O'Donnell S, Mancia F, Sun X, Nemes A, Mendelsohn M, Axel R: Odorant receptors on axon termini in the brain. Science 2004, 304(5676): | 468.

23. Strotmann J, Levai O, Fleischer J, Schwarzenbacher K, Breer $\mathrm{H}$ : Olfactory receptor proteins in axonal processes of chemosensory neurons. J Neurosci 2004, 24(35):7754-7761.

24. Wang F, Nemes A, Mendelsohn M, Axel R: Odorant receptors govern the formation of a precise topographic map. Cell 1998 , 93(I):47-60. 
25. Feinstein P, Mombaerts P: A contextual model for axonal sorting into glomeruli in the mouse olfactory system. Cell 2004, I I 7(6):817-83|.

26. Mombaerts $\mathrm{P}$ : Axonal wiring in the mouse olfactory system. Annu Rev Cell Dev Biol 2006, 22:7I3-737.

27. Zhang X, Rogers M, Tian H, Zou DJ, Liu J, Ma M, Shepherd GM, Firestein S]: High-throughput microarray detection of olfactory receptor gene expression in the mouse. Proc Natl Acad Sci USA 2004, I 0 I(39): |4|68-|4I73.

28. Gibbs RA, Weinstock GM, Metzker ML, Muzny DM, Sodergren EJ, Scherer S, Scott G, Steffen D, Worley KC, Burch PE, et al.: Genome sequence of the Brown Norway rat yields insights into mammalian evolution. Nature 2004, 428(6982):493-52I.

29. Possidente $B$, Lumia AR, McGinnis MY, Teicher $M H$, delemos E, Sterner L, Deros L: Olfactory bulb control of circadian activity rhythm in mice. Brain Res 1990, 5 I3(2):325-328.

30. Takumi T, Taguchi K, Miyake S, Sakakida Y, Takashima N, Matsubara C, Maebayashi Y, Okumura K, Takekida S, Yamamoto S, et al.: A light-independent oscillatory gene mPer3 in mouse SCN and OVLT. EMBO / 1998, I 7( I 6):4753-4759.

31. Zylka MJ, Shearman LP, Weaver DR, Reppert SM: Three period homologs in mammals: differential light responses in the suprachiasmatic circadian clock and oscillating transcripts outside of brain. Neuron 1998, 20(6): I I03-IIIO.

32. Yamaguchi S, Mitsui S, Yan L, Yagita K, Miyake S, Okamura H: Role of DBP in the circadian oscillatory mechanism. Mol Cell Biol 2000, 20( I3):4773-478I.

33. Xu J, Burgoyne PS, Arnold AP: Sex differences in sex chromosome gene expression in mouse brain. Hum Mol Genet 2002, I I ( I 2): |409-14 I9.

34. Xu J, Watkins R, Arnold AP: Sexually dimorphic expression of the $X$-linked gene Eif2s3x mRNA but not protein in mouse brain. Gene Expr Patterns 2006, 6(2):| |46-I55.

35. Xu J, Deng X, Watkins R, Disteche CM: Sex-specific differences in expression of histone demethylases Utx and Uty in mouse brain and neurons. J Neurosci 2008, 28(I 7):452 I-4527.

36. Roberts ES, Soucy NV, Bonner AM, Page T], Thomas RS, Dorman DC: Basal gene expression in male and female Sprague-Dawley rat nasal respiratory and olfactory epithelium. Inhal Toxicol 2007, I 9( I I):94I-949.

37. Jones DT, Reed RR: Golf: an olfactory neuron specific-G protein involved in odorant signal transduction. Science 1989 244(4906):790-795.

38. Scott JW, Brierley T, Schmidt FH: Chemical determinants of the rat electro-olfactogram. J Neurosci 2000, 20( I 2):472 |-473 |

39. Su Al, Wiltshire T, Batalov S, Lapp H, Ching KA, Block D, Zhang J, Soden R, Hayakawa M, Kreiman G, et al.: A gene atlas of the mouse and human protein-encoding transcriptomes. Proc Natl Acad Sci USA 2004, I 0 I ( I 6):6062-6067.

40. Cloonan N, Forrest AR, Kolle G, Gardiner BB, Faulkner G], Brown MK, Taylor DF, Steptoe AL, Wani S, Bethel G, et al.: Stem cell transcriptome profiling via massive-scale mRNA sequencing. Nat Methods 2008, 5(7):613-619.

4I. Brown Norway rats informations [http://transgenose.cnrs-orle ans.fr/taam/souches.php?s=70\&sp=rats

42. Boyce JM, Shone GR: Effects of ageing on smell and taste. Postgrad Med J 2006, 82(966):239-24l.

43. Rawson NE: Olfactory loss in aging. Sci Aging Knowledge Environ 2006, 2006(5):pe6.

44. Miller SS, Spear NE: Olfactory learning in the rat neonate soon after birth. Dev Psychobiol 2008, 50(6):554-565.

45. Wauthier V, Waxman DJ: Sex-specific early growth hormone response genes in rat liver. Mol Endocrinol 2008 22(8): 1962-1974.

46. Agilent Technologies website [http://www.chem.agilent.com]

47. TIGR Mev 4.2 [http://www.tm4.org/mev.html]

48. Dennis G Jr, Sherman BT, Hosack DA, Yang J, Gao W, Lane HC, Lempicki RA: DAVID: Database for Annotation, Visualization, and Integrated Discovery. Genome Biol 2003, 4(5):P3

49. Huang da W, Sherman BT, Lempicki RA: Systematic and integrative analysis of large gene lists using DAVID bioinformatics resources. Nat Protoc 2009, 4(I):44-57.

50. Primer 3 [http://frodo.wi.mit.edu/]

51. Livak KJ, Schmittgen TD: Analysis of relative gene expression data using real-time quantitative PCR and the 2(-Delta Delta C(T)) Method. Methods 200I, 25(4):402-408.
Publish with Bio Med Central and every scientist can read your work free of charge

"BioMed Central will be the most significant development for disseminating the results of biomedical research in our lifetime. "

Sir Paul Nurse, Cancer Research UK

Your research papers will be:

- available free of charge to the entire biomedical community

- peer reviewed and published immediately upon acceptance

- cited in PubMed and archived on PubMed Central

- yours - you keep the copyright 